\title{
试论新课改下初中物理实验教学的改进与创新
}

\author{
姚晓枫 \\ 沈阳市于洪区北陵中学 \\ DOI:10.32629/er.v2i4.1783
}

[摘 要] 随着我国教育事业的不断发展,初中物理教学模式也发生了较大的变化,如何做好物理实验教学工作已经成为各个 初中十分重要的研究课题之一。根据新课改的有关要求, 新形势下的初中物理教学工作应当进一步提高学生的学习自主性与 积极性, 重点培养学生的自主学习能力与物理思维能力。因此, 本文对新课改下初中物理实验教学的改进与创新进行了详细的 分析。

[关键词] 初中物理; 新课改; 实验教学; 改进与创新

推动教育发展离不开富有创新性和前瞻性的教学改革。 新形势下的初中物理教学工作应当对传统的教学模式进行 不断的优化与完善, 大胆采用各种新的教学技术, 不断提高 物理教学效率与教学质量, 同步推进理论知识和思维能力两 方面的教学工作, 最终实现学生综合素质的有效提升。

\section{1 现阶段初中物理教学工作普遍存在的不足}

\section{1 对实验物理教学缺乏重视力度}

教学工作者由于面临绩效考评的压力, 为了在短时间内 有效提升学生的考试成绩, 所采用的教学方法比较简单, 在 实验课教学中用大量的时间进行实验示范, 没有给学生留下 足够的主动思考和动手操作时间, 并且单纯的强调重点支持 章节, 不注重各知识点之间的横向联系。这样的教学方法虽 然能够小幅提升学生当前的考试成绩, 但却不利于学生动手 实践能力的提升。在实验教学课上, 学生们所获取的知识主 要来源于任课教师的实验示范, 并且强行记忆实验流程和实 验结果, 严重削弱了学生们的学习兴趣, 同时也很难保证学 生将所学到的知识牢牢记在心里。因此, 新形势下的初中物 理实验教学应当以学生的动手操作为主, 自主探究物理知识 原理, 加强学生对于理论知识的理解。

另外, 一些初中在物理实验设施方面的投入相对较少, 物理实验设备不够完善。致使任课教师不得不简化实验流程 甚至缩短物理实验课程的教学时间。这种现象对于学生理解 知识、掌握知识造成了比较严重的阻碍, 很难达到预期的学 习效果。因此, 各个初中应当加强对于物理实验课程的重视 力度, 加强实验设备的采购工作, 确保物理实验教学能够顺 利、有序地进行。

\section{2 依赖于固定化模式教育}

现阶段许多初中所提供的物理实验课程在安排上存在 教育模式固化的问题。任课教师为了节约教学时间, 直接将 实验流程的细节告知学生, 学生也只是单纯地根据老师的要 求进行操作, 达到预期的实验效果即停止实验教学, 没有给 学生留下反思与总结的时间, 致使学生缺乏自主探究能力的 培养, 并且论知识缺乏了解。因此, 新课改下的初中物理实验 教学工作应当让学生积极参与到实验操作中来, 通过实验通
过解决任课教师提出的问题, 并且对实验流程进行自主化的 分析与改正, 通过自主实践、自我思考来获取核心的理论知 识, 在理解的基础上加深记忆, 只有这样才能够脱离传统的 学习模式, 使学生的动手操作能力和自主探究能力得到有效 的提升, 使初中物理实验课堂更加高效、更加富有活力。

\section{2 初中物理实验的改进与创新进程思路}

2.1 倾力打造活力实验课堂

提升初中物理实验教学工作质量, 首先要创造一个富有 活力的物理课堂。新形势下的物理实验教学工作应当综合运 用各种不同的教学手段, 鼓励学生积极、主动地参与到实验 教学中, 激发学生的主体意识, 任课教师则负责为学生的动 手操作提供指导, 以保护学生实验操作安全为主, 重点负责 教学实验的组织与指导工作。比如在《密度》一节的教学中, 任何教师可以拿出一个体积较大的木块和体积较小的铁块, 让学生猜一下哪个比较重, 有的学生会直接表达意见, 有的 学生会要求教师用天平进行测量, 结果发现二者的质量完全 一致。那么就引出这样一个问题, 为什么质量相同的两个物 体体积会出现这么明显的差别? 这样就引出 “密度” 这一概 念。这时, 任课教师可以为学生发放 3 个体积相同、质量不 同的材料, 让学生通过实际测量自主探究体积、质量与密度 之间的关系, 最终得到 “ $\rho=$ ” 这一知识点。

\section{2 引导学生自制实验器材}

自制实验器材也是学生需要具备的物理素养之一, 自制 实验器材的能力能够表现出学生理论联系知识的能力与动 手实践操作能力。新课改要求任课教师组织学生自制实验所 需的器材, 一方面可以弥补学校在物理设备准备方面的不足, 同时也能够激发学生挑战困难、自主探索的勇气与决心。以 《光的直线传播》一节的现教学为例, 任何教师需要让学生 在实验的过程中了解小孔成像的原理与白光传播的基本规 律。比如在易拉罐底部打一个小孔, 用一片半透明的塑料膜 蒙在空罐的口上, 再将小孔对准小灯泡, 让学生自主观察发 光体在薄膜上呈现的像。最终得出 “光沿直线传播”的实验 结论。在此过程中, 学生通过动手自制实验器材, 能够进一步 提升学生对于实验操作的注意力, 有效提升课堂实验效果。 
2.3 通过实验培养学生的创新能力

在初中物理实验教学中, 任何教师一方面要大致介绍各 种实验器具的使用方法, 同时也要让学生积极参与进来, 提 升学生的自主思考能力和动手操作能力。物理实验教学能够 指导学生验证物理理论、观察物理现象, 对物理规律和物理 概念有一个更加深刻的理解。若任课教师单纯的让学生观察 物理现象, 而没有进行实际操作, 将严重影响实验教学效率。 因此, 任何教师应当积极鼓励学生参与动手实验。比如在《牛 顿第一定律》一节的实验教学中, 任课教师可以组织学生进 行 “叠放 6 只象棋, 敲打最下面一只棋子的实验, 被敲打的棋 子飞出去, 而上面的棋子不倒下” 的比赛, 让学生们通过游戏 的方式更加深入的理解 “惯性” 这一物理概念。在《大气压 强》这一节的实验中, 任课教师可以指导学生将 60 度的温开 水倒入塑料瓶中并将瓶盖拧紧, 再自然冷却后通过观察会发 现 “矿泉水瓶收缩” 这一现象, 进而引出 “大气压强” 这一 概念。

通过动手实验、自主观察的方法对学生的创新能力进行 培养, 能够实现物理实验教学质量的有效提升, 同时也能够 使同学们感受到物理实验的趣味性, 进而提升自主操作、自 主思考的积极性。在物理实验教学中, 任课教师应当重点做 好指导工作, 将物理实验与物理知识有机结合起来, 能够起 到事半功倍的效果。

\section{4 采用信息化教学手段}

2. 4.1 任课教师的教学策略

将信息技术应用于物理科目教学实践中, 还将重点放在 针对传统教学模式的改革与完善中。在传统教育模式下, 学 生们往往会受到学习环境的限制, 接受知识的机会相对有 限。而在信息化技术的支持下, 学生与任课教师之间的沟通、 知识内容的获取将不再受到时间与空间的限制, 实时获取教 学课件、课后习题与知识重点, 灵活性水平大幅提升。这就 要求任课教师丰富知识内容的承载形式, 在原有文本内容的 基础上, 引入图片、视频等教学内容, 通过各种不同类型的知 识载体满足学生们的学习需求, 通过影像、声音等信息传递 形态对文本资源进行适当的补充。

\subsection{2 初级中学的信息化建设策略}

将信息技术引入日常教学实践中, 学校本身要做好相关 的基础设施建设, 设置校内服务器和局域网体系, 进一步加 大在信息化建设方面的投入力度, 为学生们提供更加便利的 教育资源资讯服务, 最大程度上实现教学资源的共享。必要 情况下, 可以与专业的 IT 企业之间的合作, 既要全面落实硬 件方面的建设, 同时也要做好软件方面的建设。对于学校来 说, 软件工具的制作与应用水平将直接决定该校的信息化教 学水平, 这就需要物理科目的所有教育对教学大纲、知识重 点进行深入的挖掘, 并且提供相关的解释方案, 与 IT 工作者 加强合作, 制作出每一名学生都能够理解的动态化模拟程序, 将信息化技术在物理科目教学中的应用优势最大程度上发 挥出来。

\section{3 结束语}

新形势下的初中物理教学工作应当严格遵循新课改所 提出的有关要求, 不断拓展物理实验教学的实施路径, 创新 教学手段, 对学生们的学习需求进行深入的研究与分析。任 课教师应当坚决维持学生们在课堂上的主体地位, 通过对教 学模式的改革与创新让学生们得到更加广阔的发挥空间, 激 发学生们的学习兴趣, 引导学生们积极参与到动手实践活动 中, 重点培养学生们的自主思维能力和动手操作能力。

\section{[参考文献]}

[1]陈菲.探究趣味物理实验在中学物理教学中的实践 运用 $[J]$.科学咨询(教育科研),2018,(07):102。

[2]间明光.结合生活实际的初中物理实验教学研究 [J]. 课程教育研究,2016,(12):134-135.

[3]邱朝阳.浅析如何提升沪科版初中物理实验课堂教学 有效性[J].中学理科园地,2018,14(01):154-155.

[4]苑文领.浅谈利用综合实践活动拓展初中物理实验教 学的方法与策略[J]. 学周刊,2018,(32):51-52.

[5]杨武.试论新课改下初中物理实验教学的改进与创新 [J].科教文汇(下旬刊),2013,(12):154-155.

[6]薛刚.网络环境下初中物理实验探究式教学模式应用 探讨[J].中国教育技术装备,2016,(17):140-141。 